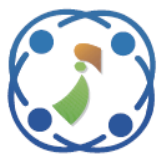

\title{
Voltage Function in Directional Over-Current Protection to Enhance the Sensitivity and Coordination Problem in Microgrid with High Penetration of Inverter-Based Resources
}

\author{
Vincentius Raki Mahindara ${ }^{1}$ \\ Ardyono Priyadi ${ }^{1}$ \\ David Felipe Celeita Rodriguez ${ }^{2}$ \\ Margo Pujiantara ${ }^{1}$ \\ Eduard Muljadi ${ }^{3}$ \\ Mauridhi Hery Purnomo, ${ }^{1,4}$ \\ ${ }^{I}$ Department of Electrical Engineering, Institut Teknologi Sepuluh Nopember, Surabaya, Indonesia \\ ${ }^{2}$ Facultad de Ingeniería, Institución Universitaria Politécnico Grancolombiano, Bogota D.C, Colombia \\ ${ }^{3}$ Department of Electrical and Computer Engineering, Auburn University, Auburn, AL, USA \\ ${ }^{4}$ Department of Computer Engineering, Institut Teknologi Sepuluh Nopember, Surabaya, Indonesia \\ * Corresponding author's Email: hery@ee.its.ac.id
}

\begin{abstract}
Integration of inverter-based resources (IBR) as a distributed generator (DG) in a microgrid has been a trend. Considering that DG integration transforms the short circuit behavior in terms of magnitude and direction in the system, the conventional protection scheme becomes no longer relevant. The major concern of the traditional protection scheme in a microgrid is the relay operating time to clear the fault in a coordinated manner. This paper presents a novel voltage-current model for directional over-current relay (DOCR) that gives the relay capability to reduce the overall relay time operation. The state-of-the-art of the proposed relay architecture relies on the adaptive pickup current threshold, which varies with the voltage magnitude, to anticipate the small fault current caused by the IBR. The improvement of relay sensitivity offers faster tripping time in a coordination scheme. The proposed method is assessed in the IEEE 13 bus distribution system with the integration of DG. The outcome of this study indicates that the total relay time operation using the proposed method is $2.363 \mathrm{~s}$. Compared to the conventional method based on the standard equation, the proposed technique significantly reduces the total relay operating time up to $47.67 \%$.
\end{abstract}

Keywords: Coordination protection, Microgrid, Over-current relay, Power system protection, Protective relaying control.

\begin{tabular}{ll}
\multicolumn{2}{c}{ Nomenclature } \\
STA & Over-current relay (OCR) state operation \\
PICK & Pickup state \\
$T R I P$ & Trip state \\
$R E S T$ & Restrain state \\
$G$ & Sensed current by OCR \\
$G_{S}$ & Preset current threshold value \\
$t$ & Timer (clock) \\
$t(G)$ & OCR time delay with respect to the sensed \\
& current \\
$M$ & Ratio between sensed current and threshold \\
$T M S$ & value \\
$T M S_{\min }$ & Time multiplier setting \\
$T M S_{\max }$ & Highest value of $T M S$ \\
$T$ & Operating torque in DOCR \\
$\phi_{i}$ & Polarizing values proportional to the current
\end{tabular}

$\phi_{v} \quad$ Polarizing values proportional to the voltage

$\varphi \quad$ Angle between $\phi_{i}$ and $\phi_{v}$

$U \quad$ Voltage bus

$G_{S}(U) \quad$ Function of current threshold associated with

voltage bus

$V C M \quad$ Voltage current multiplier

$U_{t h} \quad$ Voltage threshold in VCM

$O F \quad$ Objective function

tp Actual OCR time operation when acting as

primary protection

$t p_{\text {min }} \quad$ Minimum $t p$

$t p_{f} \quad t p$ when DOCR operates in forward direction

$t p_{r} \quad t p$ when DOCR operates in reverse direction

$t b \quad$ Actual OCR time operation when acting as

tb backup protection

CTI Certain time interval

$C T I_{\min } \quad$ Minimum CTI 


\section{Introduction}

One of the main challenges in modern power distribution systems is the inevitable integration of renewable energy resources (RES) and microgrids [1]. Such subsystems are designed and implemented by the availability and location of power electronicsbased modules. Therefore, it is critical to understand how conventional over-current protection coordination may change its philosophy with the modern context of microgrids, constantly interacting with the existing infrastructure of distribution systems [2]. Certainly, the fault behavior will be subjected to the new components and physical limitations of RES, and it urges to re-think practical protection schemes avoiding the spread of a fault.

The literature reports a wide range of approaches, and all of them aim to provide a fast and secure disconnection of the faulty section from the remaining healthy portion of the distribution power system [2]. This study is going to focus on directional over-current protection, one of the most critical relay functions that should be review carefully, which in most cases implemented as a backup for distance protection schemes. Within the context of microgrids with high penetration of inverter-based resources in distribution networks, certain challenges are expected:

- Optimization of multiple time-inverse relays [3].

- Variation of fault current levels.

- Bi-directional fault current.

- Dynamic topologies [4].

- Coordination with distribution networks.

- Multiple operation modes changing the microgrid.

- The adaptability of protection schemes.

Even though a large amount of research has been conducted with microgrid protection as the topic, most of the available protection relay in the market is not suitable for microgrid operation [5]. Particularly, directional over-current protection is one of the key schemes for feeders and distribution lines. Nevertheless, there could be a problem with implementing the same protection scheme for the high-penetration of inverter-based resources due to the low operating speed [6, 7]. Even more challenging when they are close to sub-transmission systems where traditional coordination between multiple devices (distance relays as primary protection and over current relay as back up) might no longer be sufficiently secure $[8,9]$.

The existing over-current relay (OCR) works with a conventional standard of the inverse-time equation as in ANSI/IEEE [10] or IEC [11]. The OCR work by comparing the pre-set current threshold to the actual current flows. Once the current pass the threshold, the OCR operates at a specific time. The inverse-time function determines the time operation of OCR. When the sensed current is significantly greater than the threshold, the relay operates swiftly. Conversely, when the sensed current slightly greater than the threshold, the relay produce a long-time delay.

In the context of a distribution system with high penetration of power-electronics resources, the converter's fault current is not as high as if it comes from a synchronous generator (to be discussed comprehensively in Section 2). Hence, conventional OCR requires a long-time delay before it practically isolates the fault.

Owing to the fact that the short circuit in the power system is related to the voltage dip, several studies tried to include the voltage as the protection system's parameter. The study in [12] proposed voltage reading as the main factor to determine the relay operation as a feeder protection solution to anticipate small fault current from the inverter in a microgrid. The relay time operation is in line with the voltage magnitude. To employ that kind of relay, an extensive study about the distribution system's initial condition is required to set up the coordination scheme and avoid a false-trip.

Another approach is proposed in [13]. The consideration of the voltage parameter is manifested in the conventional inverse-time equation. The study utilizes voltage as a factor to reduce the relay time operation. The study was improved in [14] by adding non-communication coordination and directional feature. The study was successful in reducing the relay total operating time. Although this may be true, the time reduction by voltage measurement contends only when the relay already in the pickup state. Thus, the relay is insensitive during the state transition from standby to the pickup state, which is considered a gap to fill in this work.

This article proposes a new approach to the standard equation by considering the voltage magnitude as a factor to spontaneously adjust the current threshold of the OCR in feeder protection. The self-adjustment from the OCR current threshold as pickup value gives the relay ability to be more sensitive to the low fault current and selective in a coordinated manner. The proposed method inherits the device requirements of selectivity, sensitivity, and adequate protection coordination by modifying the traditional time current response with a voltage variable dependability. Such features overcome the harmonics-based directional methods for microgrids, which cannot be used for non-inverter-based 
resources [15]. Simulation results demonstrate that the proposed method performed well with a microgrid. It executed safe protection and reduced the total time operations compared to the preceded literature in [10-14].

The paper is organized as follows: the brief review of the microgrid's fault behavior is discussed in Section 2. The proposed method is described in Section 3. The test system based on the IEEE 13 bus test feeder and its scenario are presented in Section 4. The simulated results and extensive analysis in coordination and time response of the proposed method are presented in Section 5. At last, Section 6 concludes the paper with a brief discussion and future implementation.

\section{Abnormal event in microgrid distribution network}

The microgrid concept in a power system is applied to a network that contains a source and sinks with local control and the ability to operate either islanded or connected to the grid [16]. A source in a microgrid is defined as a distributed energy resource (DER). The word "distributed" means the penetration points could be anywhere at various buses or nodes. Hence, at a certain point, the DER penetration could be very useful to minimize the losses in the system. However, the penetration might pose another distressing challenge to the conventional distribution network.

Originally, the distribution system's regular infrastructure is intended for a radial topology where the power comes from a single source [17]. Therefore, when the DER penetrates, the operation and the protection system of the conventional distribution network might be impacted [18]. Fig. 1 illustrates one of the impacts of DER penetration in the distribution network. When the system is supplied from a single source, the current flow direction is unidirectional from the grid. This condition only requires R1 to operates if there is a fault (illustrate as F in B-1). In contrast, when the distributed generator (DG) is included in the system, the presence of DG might reduce the transferred power from the grid. Another protection device is required to operate during fault conditions because two sources supply the faulted bus, in forward and reversed direction [19] of the R1 and R2, respectively. Hence, R1 and R2 shall trip simultaneously to mitigate the fault which caused $I_{F(\text { Grid })}$ and $I_{F(D G)}$, respectively.

The DER covers all possible types of generators (e.g., fossil or biomass-fired power, photovoltaic module, wind turbines, hydropower, etc.) and storage

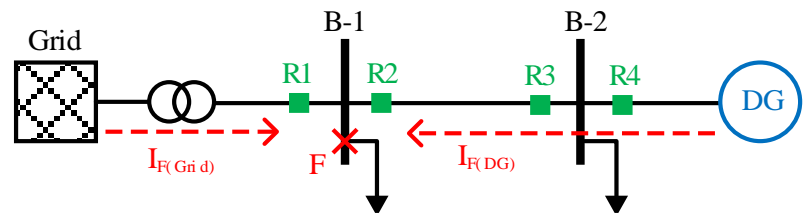

Figure. 1 Single line diagram for a distribution network with DG penetration. During fault, the fault current from

$\mathrm{DG}\left(\mathrm{I}_{\mathrm{F}(\mathrm{DG})}\right)$ has opposite direction than the grid fault current

devices (e.g., batteries, flywheel, super-capacitor, etc.) [20-22]. Based on the type of connection, the DER in the microgrid could be categorized into an electrical machine, either induction or synchronous machine, and inverter-based resource (IBR).

Accordingly, this type of DER has a different dynamic response to the short circuit event. The short circuit response of a machine-based source, such as a synchronous generator (SG), depends on the reactance value that changing during sub-transient, transient, and steady-state time-domain [23]. Hence, during short circuit analysis, the SG is modeled as a voltage source. On the other hand, the IBR has a completely different response to the SG. Most of the IBR is modeled as a voltage-controlled current source [24], which relies on the rotating reference frame control unit. During the operation, the short circuit response of the IBR is limited to 1.2 p.u. to prevent the destruction of the internal electronic component. The fault current magnitude of IBR is way smaller than the SG [25]. Thus, the small fault current from IBR might not be sensed by the conventional protection device or requires a longer time response.

To illustrate the comparison of fault current from SG and IBR, the time-current curve is shown in Fig. 2, concerning the same fault location as in Fig. 1, under different DG models. When the DG is modeled as the $S G(D G=S G)$, the primary relay in reverse direction, $\mathrm{R} 2$, trips immediately and could be backedup by $\mathrm{R} 4$ at a specific interval time ( $\Delta t \mathrm{R} 4-\mathrm{R} 2$ $(\mathrm{DG}=\mathrm{SG})$ ). However, when the $\mathrm{DG}$ is modeled as the IBR (DG=IBR), the response time of R2 and R4 is longer compared to the DG as SG. Correspondingly, the interval time ( $\Delta t \mathrm{R} 4-\mathrm{R} 2$ (DG=IBR)) might be affected as well.

\section{The role of protection system in microgrid distribution network}

The distribution network's protection system holds a big responsibility to isolate any abnormal event, in any condition, either with DG penetration or a single power source operation, with minimum damage and impacted zone. The protection system's 


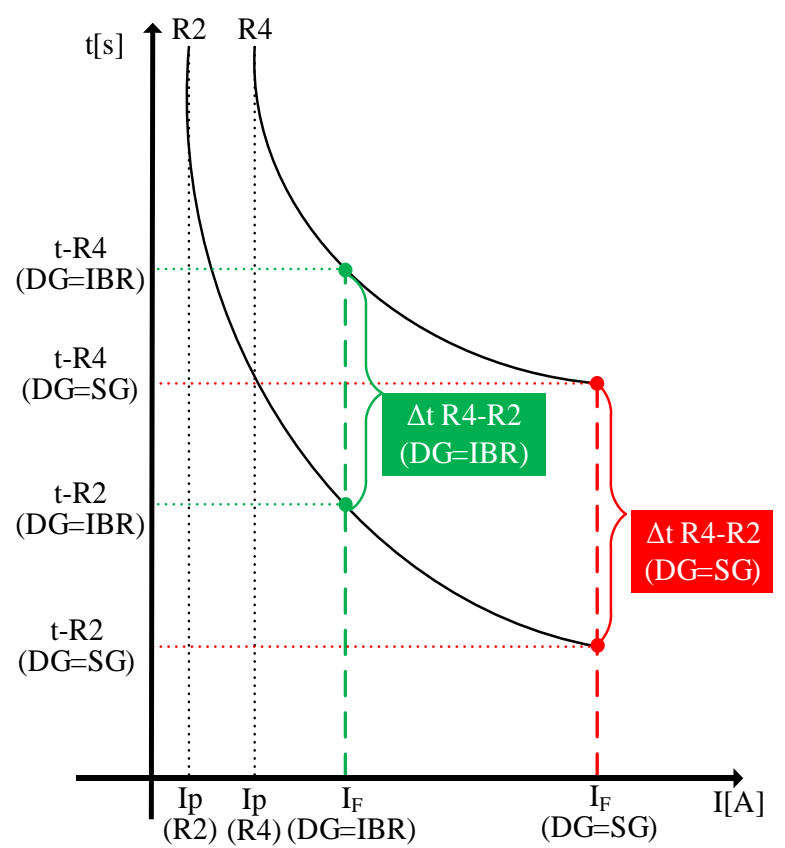

Figure. 2 The time current curve shows the impact of varying fault current magnitude to the relay time response

philosophy shall in a trade-off point between the power system reliability and stability [26]. Thus, the protection system shall be sensitive and selective at the same time to mitigate the unordinary condition.

The protection system is constituted of several devices that work coordinately. Each device has different function but the same objective to secure the power system.

\subsection{The principle of over current protection}

According to IEC Standard 60255-151 [11], the operation of OCRs could be expressed by using a characteristic curve. There are two types of characteristics, which are independent and timedependent. Another standard, IEEE Std. C37.2 [27] specified the device number as ANSI 50 and 51 for independent and time-dependent, respectively. In this paper, the discussion is limited to the dependent time characteristic relay (ANSI 51).

The operation of OCR is determined by its state (STA), either pickup (PICK), trip (TRIP), or restrained (REST) condition. The OCR operates in a restrained state under normal conditions. When the sensed current ( $G$ ) exceeds the preset current threshold value $\left(G_{S}\right)$, the relay goes to the pickup state. Once the timer $(t)$ passed the time delay $(t(G))$, the relay shall send a trip signal to the circuit breaker. Thus, the relay goes to trip state. TRIP also known as time-out state. This operation might be described by the following equation:

$$
S T A(O C R)= \begin{cases}P I C K, & G>G_{S} \\ T R I P, & G>G_{S} \text { and } t \geq t(G) \\ R E S T, & G \leq G_{S}\end{cases}
$$

The $t(G)$ in inverse-time characteristics varies with the sensed current. Given this context, the time delay shall form a function, where the increasing magnitude of $G$ shall be followed by decreasing value of time delay. To give a certain limit to the $t(G)$, the magnitude of $G$ shall be compared to the $G_{S}$, which form a ratio called $M$. This ratio might be formulated as:

$$
M=\frac{G}{G_{s}}
$$

The ratio of $M$ could be used to update the status of OCR in Eq. (1). Later, the relation between $M$ and OCR operation could be written as:

$$
S T A(O C R)= \begin{cases}P I C K, & M>1 \\ T R I P, & M>1 \text { and } t \geq t(G) \\ R E S T, & M \leq 1\end{cases}
$$

in which $k, \alpha$, and $c$ are the standards' constant characterizing the selected curve (e.g., inverse, very inverse, extremely inverse). The selection of the curve substantially affects the time-current response.

In order to distinguish the current direction due to multiple injection point of the DER, a directional element become a basic prerequisite of OCR operation. One of the methods to detect the current direction is by using the voltage reference, which is commonly used in the relay available in the market [28-30]. In a simple word, the power direction is determined by the angle between current and voltage [31]. By considering the current and voltage as magnetic fluxes, the induced current form a rotating torque, which could be defined as [32]:

$$
T=K \times \phi_{i} \times \phi_{v} \times \sin \varphi
$$

where $K$ is the constant. The torque direction is determined by the value of $\varphi$, which is positive when $0^{\circ}<\varphi<180^{\circ}$ and negative when $180^{\circ}<\varphi<$ $360^{\circ}$. The positive and negative torque could be deciphered as forward or reverse current direction. In a normal condition, the relay usually works in a forward direction, i.e., when the relay is positioned in a downstream power system.

\subsection{Formulation of the proposed method}

The time response of an inverse OCR is mainly subject to the current flow. Based on Eq. (3), the OCR 
starts to respond when $G$ greater than $G_{S}$, in other words, $M>1$. Aforementioned in section II, the insignificant fault current from IBR, presumed as $G$, might not trigger $(M \leq 1)$ and creating a huge amount of time delay for the OCR because the $G$ is just slightly greater than $G_{S}$. To overcome the issue, this paper proposed the inclusion of voltage measurement as a factor in $t(G)$. The basic idea is to increase the value of $M$ by reducing the $G_{S}$ during fault condition. The trigger to reduce $G_{S}$ comes from the voltage suppression events during fault. In the following subsection, the relation between $G_{S}$ and the bus voltage is discussed.

\subsubsection{Mathematical model}

As mentioned in some research [22], [33-35], the voltage becomes very vulnerable when the fault occurs in a highly penetrated IBR microgrid network. The bus which is closer to the fault location will experience a severe voltage drop compared to other buses. Given this context, it might be anticipated by opening the feeder linked to the provoked bus to contain the fault. This paper proposed an idea to treat the voltage drop due to fault to lower the $G_{s}$, current threshold or relay pickup value, which increase the ratio of $M$. To conjoin the voltage parameter $(U)$ into the OCR time response, Eq. (2) might be updated to be:

$$
M=\frac{G}{G_{S}(U)}
$$

Employing Eq. (6) to replace (2) means the OCR response is no longer hinge on a $G_{S}$ as a constant, but $G_{S}(U)$ as a function. The mathematical expression of $G_{S}(U)$ is formed as:

$$
G_{S}(U)=G_{S} \times V C M
$$

The voltage-current multiplier, $V C M$, is a factor that varies along with the measured voltage bus. The $V C M$ ranges from 0.1 to 1 and become unity when the bus operates at the normal voltage condition, simply said Eq. (6) equal with Eq. (2). Thus, the relays' sensitivity remains unchanged in normal condition. However, when the voltage drops due to a short circuit in the system, the $V C M$ value decreased. To have a specific trigger on when the $V C M$ have to start decrease, a voltage threshold $\left(U_{t h}\right)$ is introduced. The decreasing value of $V C M$ leads to a decrement of $G_{S}(U)$ in Eq. (7) and increment of $M$ in Eq. (6). The rising value of $M$ urges a short OCR time operation in Eq. (4). On the other hand, when the bus experiencing an overvoltage phenomenon, the value of $V C M$ shall remain at the unity point. Considering this boundary, the following expression limits the value of $V C M$ :

$$
V C M= \begin{cases}V C M, & 0.1<U \leq U_{t h} \\ 1, & \text { otherwise }\end{cases}
$$

To construct the $V C M$, a specific equation is used as follows:

$$
V C M=\left(\frac{U}{n_{a}}\right)^{n_{b}}+n_{c}
$$

where $n_{a}, n_{b}$, and $n_{c}$ are a constant that forming the contour of VCM. $n_{a}, n_{b}$, and $n_{c}$ are self-tuned. The default value of $n_{a}$ shall be equal to one. $n_{a}$ affects the linear sensitivity of the $V C M$. When $n_{a}$ less than one, the $V C M$ become more sensitive. In contrast, to make $V C M$ less sensitive, the $n_{a}$ shall greater than one. The value of $n_{b}$ gives an exponential influence to the VCM, such a feature which essential when deals with significant voltage suppression. In default, the $n_{b}$ shall be greater than zero. The $n_{c}$ could be denoted as a positive offset for the VCM. Hence, $n_{c}$ is limited between 0.1 and 1 to comply with Eq. (8).

To control the sensitivity of the VCM, an appropriate tuning between $n_{a}$ and $n_{b}$ becomes compulsory. If the OCR shall respond in linear with the voltage drop, then the value of $n_{a}$ and $n_{b}$ shall be one. On the other hand, if the OCR response should not be too sensitive to the voltage drop, then the value of $n_{a}$ shall be greater than $n_{b}$. To put it differently, when the OCR shall be susceptible to the voltage drop, then the value of $n_{a}$ shall be less than $n_{b}$. The combination of $n_{a}, n_{b}$, and $n_{c}$ formed a $V C M$ solution that obeys the rule in Eq. (8). Fig. 3 gives an illustration of several forms of Eq. (9).

To sum up, Eq. (4) could be amended to be a final form of time-current response with regard to the voltage function as:

$$
t(G)=T M S \times\left(\frac{k}{\left(\frac{G}{G_{S}(U)}\right)^{\alpha}-1}+c\right)
$$

\subsubsection{Relay architecture}

Fig. 4 (a) shows the relay connection with the measuring apparatus. The relay measures the current flows and bus voltage and sends the tripping signal to the circuit breaker. The architecture of the relay is 


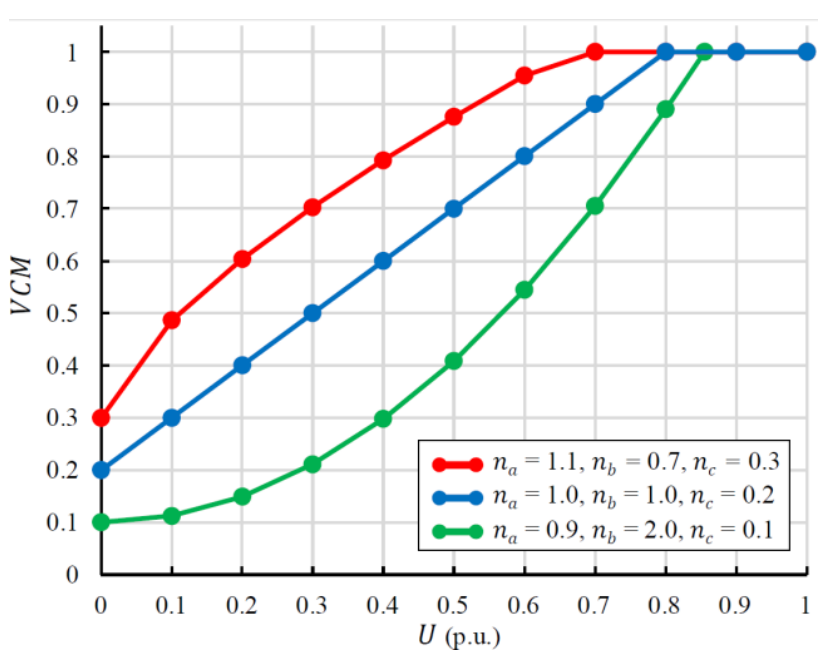

Figure. $3 V C M$ response to the drop under some combination of coefficient $n_{a}, n_{b}$, and $n_{c}$ in (9)

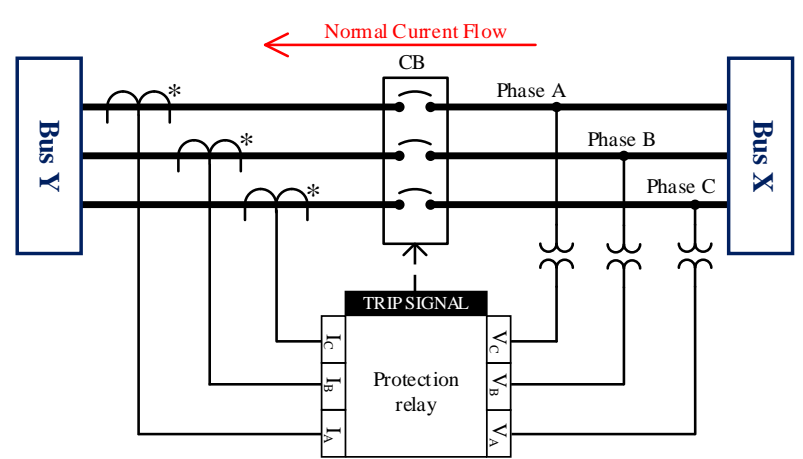

(a)

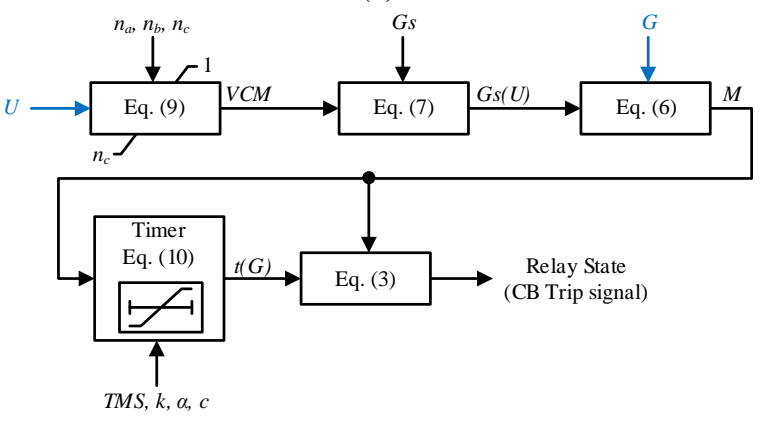

(b)

Figure. 4: (a) general assembly of proposed relay connection and (b) block diagram of the proposed relay architecture. The blue line shows the analog input from voltage and current measurement

shown in Fig. 4 (b). The relay employs the voltage and current input altogether, as explained in the previous subsection. Compared to the conventional relay, the presence of $V C M$ affects the Gs to be $G s(U)$, whichimproves the time operation, $t(G)$, and offers faster tripping time.

\subsubsection{Obtaining Relay Setting for Coordination}

This subsection presents the coordination setup of the proposed method. The relay coordination objective is to minimize the total relay operating time in the system without violating the conditions. Hence, the objective function $(O F)$ could be written as:

$$
\text { Minimize: } O F=\sum_{x=1}^{Q} \sum_{y=1}^{R}\left(t p_{f, x y}+t p_{r, x y}\right)
$$

where $Q$ is the total fault point considered in the system, with $x$ being the identifier. $R$ is the total number of relays in the system, with $y$ being the identifier. Simply said, the $O F$ is the summation of the relay time operation when acting as primary protection $(t p)$, either in forward or reverse direction, in various fault point considered in the test system. When acting as the backup, the relay time operation is denoted as $t b$. The value of $t p$ and $t b$ is determined using the time-current function as in Eq. (4) for the conventional method or Eq. (10) for the proposed method.

The $O F$ in Eq. (11) is followed by several constraints in forming the coordination scheme in the protection system. The protection relay in a distribution system shall operate in a chronological and sequence manner [36]. Hence, a certain time interval, CTI, becomes compulsory to manage the grading time. In a same fault point, the time separation between backup and primary relay can be expressed as:

$$
t b_{x}-t p_{x} \geq C T I, \quad C T I \geq C T I_{\min }
$$

A note to be taken is that there could be multiple relays that role as primary protection in a specific fault point. Also, more than one relay that role as a backup to the primary role relay The CTI applied only to the specific primary and backup relay pair to mitigate a certain fault point. The IEEE Std. 242 [37] suggest $0.2 \mathrm{~s}$ as the $C T I_{\min }$ for coordination of electronic protection apparatus.

Another constraint to comply is the prevention to relay operation during the temporary fault or subtransient condition. Hence, the minimum time operation of primary role protection $\left(t p_{\min }\right)$ is applied and can be expressed as follows:

$$
t p \geq t p_{\min }
$$

The reference in [38] suggest the value of $0.1 \mathrm{~s}$ for the $t p_{\min }$ with assumption that the temporary fault or sub-transient does not occurs more than five cycles.

Inside the relay setting, as in Eq. (4) and (10), the $T M S$ plays an important role to adjust the relay time response. The TMS has the minimum and maximum 
value, which is $T M S_{\min }$ and $T M S_{\max }$. Thus, the $T M S$ constraint is defined by

$$
T M S_{\min } \leq T M S \leq T M S_{\max }
$$

The value of $T M S_{\min }$ and $T M S_{\max }$ depends on the relay manufacturer. This paper considers the value of 0.05 and 10 for $T M S_{\min }$ and $T M S_{\max }$, respectively.

\section{Simulation Setup}

An experimental simulation was conducted using PSCAD software. The IEEE 13 bus radial distribution system was selected as the test bench, as shown in Fig. 5. The normal power flow of the IEEE 13 bus system comes only from the grid. Later, the original IEEE 13 bus test system is modified by inserting the 3 MVA IBR as the DG. The DG is considered as an IBR which operates at its full capacity and unity power factor. There are five possible fault points (F1 to F5) with seven relays (R1 to R7) considered in the test system. The relays in the test system have the capability of measuring the current flow and bus voltage. R1, R2, and R3 measures the voltage of Bus 632. R4, R5. R6 measures the voltage of Bus 671. Lastly, R7 measures the voltage of Bus 675 .

Prior to the testing, a short circuit study is performed. A three-phase symmetrical short circuit is simulated in each fault point and observed in each relay perspective. Table 1 provides the measurement result of bus voltage magnitude during the fault, considered as $U$ in the optimization process. In addition, Table 2 provides the fault current in the feeder measured by the relay. The value in Table 2 is considered as $G$ in the optimization process.

The negative value in Table 2 indicates the reverse current flow direction. Thus, a directional feature in the relay is required. The normal current flow (supplied by the grid only) is considered as a forward direction. $\mathrm{R} 2$ and $\mathrm{R} 4$ protect the same feeder. Thus, $\mathrm{R} 2$ is considered for reverse direction only ( $R 2 r$, where the current flow from Bus 671 to Bus 632) while R4 for forward direction only (R4f, where the current flow from Bus 632 to Bus 671). The bidirectional relay is R6, modeled as R6f when the current flows from Bus 671 to Bus 692 and R6r when the current flows from Bus 692 to Bus 671. Hence, the total relay being optimized become eight.

Since there is a possibility of multi-direction fault current, the coordination is categorized into three types. First, a unidirectional relay pair of a primary and backup role such as 1) R4f and R1f, and 2) R6r and R7f for fault at F2. 3) R6f and R4f for a fault at F3. 4)
R2r and R6r for a fault at F4. Second, a bi-directional relay pair where the primary role relay has two backup relays from a different feeder. For example, during fault at F1, the primary relay is R5f, and the backup pairs are $\mathrm{R} 4 \mathrm{f}$ (to anticipate the current from the grid) and R6r (anticipate the current from the DG). A similar condition also appears during fault at F5, where R3f role as primary relay and supported by two backups, R1f from the grid side and R2r from the IBR side. Third, a relay without any backup pair such as R7f during fault at $\mathrm{F} 3$ and R1f during fault at F4.

In order to assess the effectiveness of the proposed method, the over-current protection problem is solved using three different methods: the conventional technique [11] (based on Eq. (4)), the technique in[14], and the proposed method (based on Eq. (10)). Thus, some parameters are required during the simulation, as provided in Table 3. Some parameters are uniform for all methods, i.e., a selection curve type based on [11], $t p_{\min }$ as suggested in [38], CTI $I_{\min }$ as suggested in [37],

Table 1. Voltage in each relay during fault

\begin{tabular}{|c|c|c|c|c|c|c|c|}
\hline \multirow{2}{*}{$\begin{array}{l}\text { Fault } \\
\text { Point }\end{array}$} & \multicolumn{7}{|c|}{$U(\mathbf{p u})$} \\
\hline & R1 & R2 & R3 & R4 & R5 & R6 & R7 \\
\hline F1 & 0.43 & 0.43 & 43 & & 15 & & \\
\hline $\mathrm{F}$ & & & & & & & \\
\hline 53 & 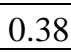 & & & & & 8 & 0.00 \\
\hline $\mathrm{F}$ & 0 & $\overline{0.0}$ & 0.00 & & 00 & 0. & 0.0 \\
\hline $\mathrm{F} 5$ & 0.16 & 0.1 & 0.1 & 0. & 0. & $0.1^{\prime}$ & 0. \\
\hline
\end{tabular}

Table 2. Current flows in each relay during fault

\begin{tabular}{|c|c|c|c|c|c|c|c|}
\hline \multirow{2}{*}{$\begin{array}{c}\text { Fault } \\
\text { Point }\end{array}$} & \multicolumn{7}{|c|}{$\boldsymbol{G}(\mathbf{A})$} \\
\cline { 2 - 8 } F1 & 2850 & 2850 & 0 & 2850 & 3010 & -442 & 442 \\
\hline F2 & 3350 & 3350 & 0 & 3350 & 0 & -519 & 519 \\
\hline F3 & 3120 & 3120 & 0 & 3120 & 0 & 3120 & 524 \\
\hline F4 & 4990 & -509 & 0 & -509 & 0 & -509 & 509 \\
\hline F5 & 4210 & -430 & 4360 & -430 & 0 & -430 & 430 \\
\hline
\end{tabular}

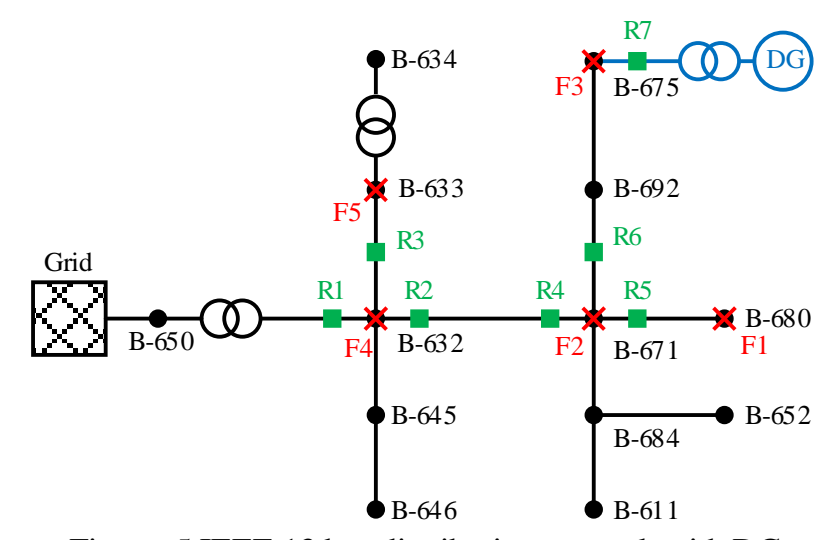

Figure. 5 IEEE 13 bus distribution network with DG penetration at end point feeder 
Table 3. Parameters used in the simulation

\begin{tabular}{|l|c|c|c|}
\hline \multicolumn{1}{|c|}{ Parameter } & Conventional [11] & Balyith [14] & Proposed \\
\hline Curve type & $\begin{array}{c}\text { Inverse type [11] } \\
k=0.14, \alpha=0.02, c=0)\end{array}$ & $\begin{array}{c}\text { Inverse type [11] } \\
k=0.14, \alpha=0.02, c=0)\end{array}$ & $\begin{array}{c}\text { Inverse type [11] } \\
(k=0.14, \alpha=0.02, c=0)\end{array}$ \\
\hline$t p_{\min }[37]$ & $0.1 \mathrm{~s}$ & $0.1 \mathrm{~s}$ & $0.1 \mathrm{~s}$ \\
\hline$T M S_{\min }$ & 0.05 & 0.05 & 0.05 \\
\hline$T M S_{\max }$ & 10 & 10 & 10 \\
\hline$C T I_{\min }[38]$ & $0.2 \mathrm{~s}$ & $0.2 \mathrm{~s}$ & $0.2 \mathrm{~s}$ \\
\hline $\begin{array}{l}G_{s} \text { factor to the nominal } \\
\text { current }\end{array}$ & 1.1 & 1.1 & 1.1 \\
\hline $\begin{array}{l}\text { Internal parameter for } \\
\text { voltage factor }\end{array}$ & - & $\beta=0.7$ & $\begin{array}{c}n_{a}=0.9, n_{b}=2, n_{c}=1, \\
U_{t h}=0.8\end{array}$ \\
\hline
\end{tabular}

$T M S_{\min }$ and $T M S_{\max }$, and $G_{S}$ factor. The value of $T M S_{\text {min }}, T M S_{\text {max }}$, and $G_{s}$ factor are pre-assumed in this work. Furthermore, a unique parameter, known as $\beta$, also required for technique in [14] which obtained in the self-tuning. In the proposed method, the parameters of $n_{a}, n_{b}, n_{c}$, and $U_{t h}$ are self-tuned to form a sensitive relay when voltage suppression occurs.

\section{Simulated Result and Discussion}

The effectiveness of each method is judged by the relay total operating time in the test system. Also, the techniques are analyzed in two terms: 1) the optimal setting and time operation for relay coordination and 2) relay response during fault and its changing state response.

\subsection{Relay Coordination}

The optimization variable in Eq. 11 is the setting for the whole relay in the test case system, considering several fault points. The optimization model is solved using MATLAB linear programming toolbox. Table 4 provides the result of optimized relay settings using various methods. As can be seen from the results, the TMS value is different for each method. In the conventional method based on

Table 4. Optimized relay settings among methods

\begin{tabular}{|l|c|c|c|c|}
\hline \multirow{2}{*}{ Relay } & $\boldsymbol{G}_{\boldsymbol{s}}(\mathbf{A})$ & $\begin{array}{c}\text { Convent- } \\
\text { ional } \\
{[\mathbf{1 1}]}\end{array}$ & $\begin{array}{c}\text { Balyith } \\
{[\mathbf{1 4}]}\end{array}$ & Proposed \\
\hline R1f & 625.1 & 0.124 & 0.185 & 0.237 \\
\hline R2r & 139.7 & 0.050 & 0.087 & 0.139 \\
\hline R3f & 77.8 & 0.060 & 0.108 & 0.092 \\
\hline R4f & 457.9 & 0.089 & 0.160 & 0.201 \\
\hline R5f & 80 & 0.054 & 0.098 & 0.086 \\
\hline R6f & 186.1 & 0.050 & 0.079 & 0.096 \\
\hline R6r & 393.1 & 0.050 & 0.050 & 0.171 \\
\hline R7f & 438.2 & 0.050 & 0.050 & 0.236 \\
\hline
\end{tabular}

standard equation (Eq. 4) [11], the TMS is obtain without any consideration to the voltage bus. The difference of optimized TMS value in the proposed method appears because of the varying value of

$G_{S}(U)$ compared to the fixed $G_{s}$ in the conventional method.

Once the optimized TMS obtained, its value is used to calculate each relay time operation. Table 5 contains the relay operating times under various fault locations and coordination scenarios. All methods satisfy the coordination constraints, i.e., $t p_{\min }$ and CTI $I_{\text {min }}$.

The relays' sensitivity is judged by the time required to anticipate the fault. In all methods, the relays are not over-sensitive since they comply with the minimum operating time constraint to intercept the fault when acting as primary protection. However, an in-depth analysis of primary role protection shows that the conventional method creates an insensitive relay, especially when it deals with IBR's fault current. For example, during fault at F2, R6r requires 1.256 s before it operates as primary protection. Such a long time to isolate the fault for the conventional method. The technique in [14] able to reduce the time operation to be $0.624 \mathrm{~s}$. The proposed method significantly curtails the time operation reduction to be $0.451 \mathrm{~s}$. In another case, fault at F3, R7f requires $1.955 \mathrm{~s}$ when using the relay setting from the conventional method, $0.971 \mathrm{~s}$ when using the relay setting from the technique in [14], and $0.648 \mathrm{~s}$ when using the relay setting offered by the proposed method. Unlike when the relay deals with fault current from IBR, all methods are sensitive, shown by the similarly minimum time operation, when the fault current is also contributed from the grid (modeled as a synchronous generator). For example, during fault at F1, the R5f time operation is $0.1 \mathrm{~s}$ for all methods. The facts prove that the proposed method capable of deals with fault current from grid or IBR. The relay time operation in the proposed method has 
Table 5. Relay operating times among methods in various fault point

\begin{tabular}{|c|c|c|c|c|c|c|c|c|}
\hline \multirow{2}{*}{ Fault Point } & \multirow{2}{*}{ Relay } & \multirow{2}{*}{ Role } & \multicolumn{2}{|c|}{ Conventional [11] } & \multicolumn{2}{|c|}{ Balyith [14] } & \multicolumn{2}{|c|}{ Proposed } \\
\hline & & & $t(G)$ & CTI & $t(G)$ & CTI & $t(G)$ & CTI \\
\hline \multirow[t]{3}{*}{$\mathrm{F} 1$} & R5f & Primary & 0.100 & & 0.100 & & 0.100 & \\
\hline & $\mathrm{R} 4 \mathrm{f}$ & Backup & 0.336 & 0.236 & 0.331 & 0.231 & 0.348 & 0.248 \\
\hline & R6r & Backup & 2.984 & 2.884 & 1.644 & 1.544 & 0.536 & 0.436 \\
\hline \multirow[t]{4}{*}{$\mathrm{F} 2$} & R4f & Primary & 0.308 & & 0.273 & & 0.314 & \\
\hline & R1f & Backup & 0.508 & 0.200 & 0.473 & 0.200 & 0.514 & 0.200 \\
\hline & R6r & Primary & 1.256 & & 0.624 & & 0.451 & \\
\hline & R7f & Backup & 2.065 & 0.809 & 1.035 & 0.411 & 0.651 & 0.200 \\
\hline \multirow[t]{3}{*}{ F3 } & R6f & Primary & 0.121 & & 0.100 & & 0.126 & \\
\hline & $\mathrm{R} 4 \mathrm{f}$ & Backup & 0.321 & 0.200 & 0.300 & 0.200 & 0.326 & 0.200 \\
\hline & R7f & Primary & 1.955 & & 0.971 & & 0.648 & \\
\hline \multirow[t]{3}{*}{ F4 } & $\mathrm{R} 2 \mathrm{r}$ & Primary & 0.267 & & 0.232 & & 0.261 & \\
\hline & R6r & Backup & 1.352 & 1.084 & 0.695 & 0.463 & 0.461 & 0.200 \\
\hline & R1f & Primary & 0.409 & & 0.302 & & 0.363 & \\
\hline \multirow[t]{3}{*}{ F5 } & R3f & Primary & 0.100 & & 0.100 & & 0.100 & \\
\hline & R1f & Backup & 0.446 & 0.346 & 0.370 & 0.270 & 0.407 & 0.307 \\
\hline & $\mathrm{R} 2 \mathrm{r}$ & Backup & 0.308 & 0.208 & 0.300 & 0.200 & 0.300 & 0.200 \\
\hline
\end{tabular}

Table 6. Total operation time based on $O F$ and the effectiveness among methods

\begin{tabular}{|l|c|c|}
\hline \multicolumn{1}{|c|}{ Method } & $\boldsymbol{O F}$ & $\begin{array}{c}\text { Time reduction } \\
\text { benchmark (\%) }\end{array}$ \\
\hline Conventional [11] & 4.516 & - \\
\hline Balyith [14] & 2.702 & $40.16 \%$ \\
\hline Proposed & 2.363 & $47.67 \%$ \\
\hline
\end{tabular}

faster tripping time since its capability to readjust the relay pickup value to increase the $M$ ratio during a fault, which leads to lower $t(G)$.

The effectiveness of each method is examined from the total relay time operation in the test system. As formulated in Eq. 11, the total relay time operation, known as $O F$, consider all fault point in the test system. Table 6 enclose the $O F$ of each method. The total relay time operation in the conventional method is $4.516 \mathrm{~s}$, which is seen as a benchmark. The technique in [14] result $O F$ with value 2.702 s, which equivalent with $40.16 \%$ reduction from the benchmark. The proposed method result $O F$ with value $2.363 \mathrm{~s}$, which equivalent with $47.67 \%$ reduction from the benchmark and $12.54 \%$ reduction from the technique in [14]. Thus, it might be concluded that the proposed method offers more effective result when deals with a microgrid with penetration from IBR.

\subsection{Relay State Response Analysis}

This subsection provides the performance analysis of the proposed method in a time response oscillograph. Suppose the fault occurs in F1 and R5f (which is supposed to act as primary protection) fails to trip the CB. The backup protection for fault at F1 is R4f and R6r. The analysis is focused on R6r, which sensed the fault current from the IBR.
Fig. 6 (a) shows the current response during the simulation. In normal condition the $G_{S}$ and $G_{S}(U)$ of R6r had the same value of 393.1 A, while the current flow below the relay pickup value. When the fault occurs at $\mathrm{t}=0.1 \mathrm{~s}$, the current raising and the $G_{S}(U)$ decreasing from its original value. The decrement of $G_{S}(U)$ in the proposed method result in a $0.099 \mathrm{~s}$ faster pickup time compared to the constant $G_{S}$ in the conventional method. Since the increasing of current and the decreasing of $G_{S}(U)$ occur simultaneously, the $M$ ratio in the proposed method expands faster than the conventional method. The faster relay pickup time gives an advantage to the relay to start the counter before tripping. Fig. 6 (b) shows the relay tripping status. The proposed method has a faster tripping time (0.401s after relay pickup) than the conventional method (2.75s after relay pickup). The superiority of faster pickup and tripping time in the proposed method relies on the voltage measurement, as shown in Fig. 6 (c). During fault at F1 (Bus 680), the voltage in Bus 671 drops and affects the $G_{S}(U)$ of R6r. Once the fault is cleared, the voltage returns normal. In contrast, if the relay insensitive to the fault (as simulated in the conventional method), the voltage drop still occurs at the bus.

\section{Conclusions}

This paper recognizes the issue of high penetration of IBR in the microgrid while proposes the inclusion of voltage function in DOCRs operation. The state-of-the-art of this paper is the voltagecurrent model that makes the relay has the capability to readjust the pickup value so that the relay could adapt to the small fault current caused by the IBR. 


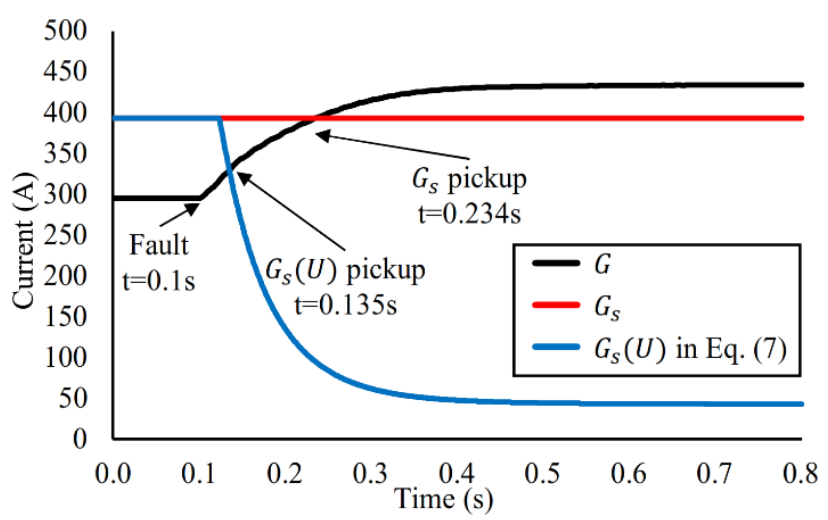

(a)

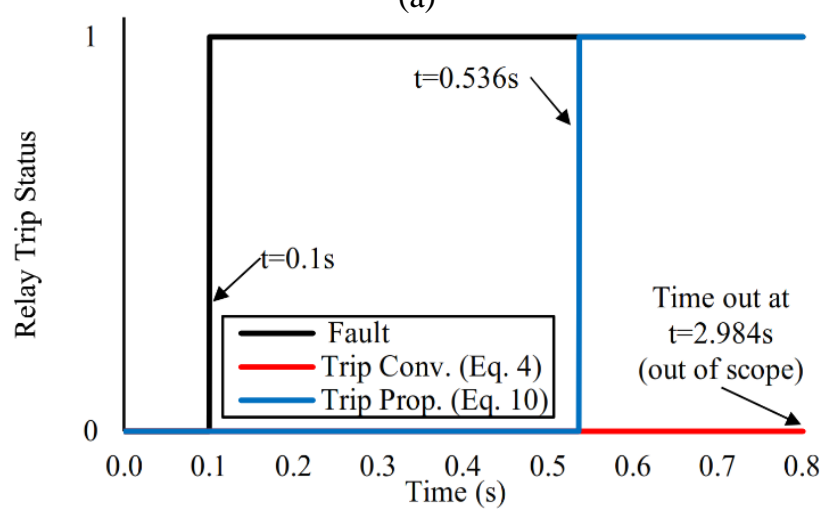

(b)

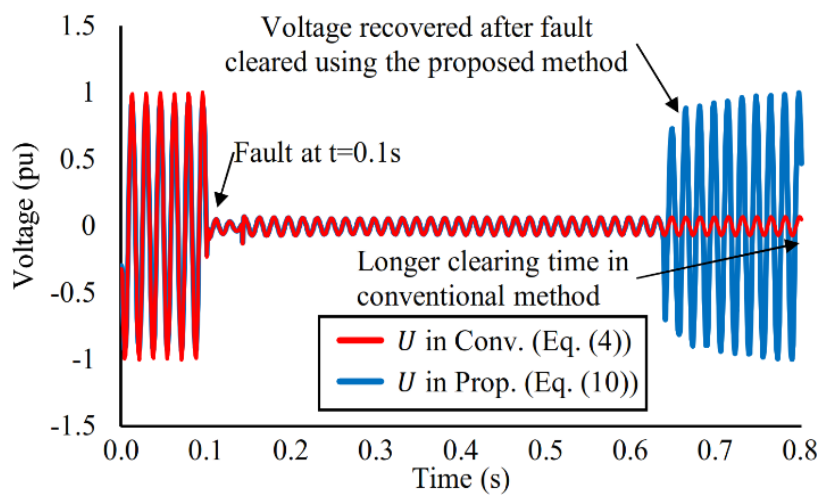

(c)

Figure. 6 Comparison between the conventional and the proposed method: (a) RMS current oscillography at R6r during fault at F1 compared to the relay pickup current, (b) Tripping chart of R6r, and (c) Comparison of the voltage oscillography at Bus 671

Adaptation of the pickup value in the protection relay offers faster tripping time in a coordination scheme.

The proposed method was validated using the standard IEEE 13 bus distribution system with the insertion of DG, and the performance was compared to the conventional over-current relay model. The relay setting was obtained by solving the optimization problem to minimize the relay primary time operation subject to the coordination scheme constraints. Several fault points applied to the test system to evaluate the performance of the model. The results clearly indicate that the proposed method has a lower total relay operating time than the conventional standard equation and preceded works without any violation to the

coordination constraints. The total relay operating time using the proposed method is $2.363 \mathrm{~s}$, which $47.67 \%$ more efficient compared to the conventional method. The time-domain analysis shows that the proposed technique gives the relay ability to vary the pickup value (current threshold) accordingly with the fault location. Thus, increase the sensitivity and selectivity of the relay compared to the conventional method during fault anticipation.

For the main contribution, this work incorporates the voltage bus as a parameter to trigger the relay since the small fault current from IBR creates a long-time delay to the original DOCR. It is found that with a proper setting, the proposed model could work in a coordinated manner, just like the conventional DOCR. Hence, the proposed model is feasible for implementation in the real system.

\section{Conflicts of Interest}

The authors declare no conflict of interest.

\section{Author Contributions}

Conceptualization, Vincentius Raki Mahindara, Margo Pujiantara, Ardyono Priyadi, and Mauridhi Hery Purnomo; methodology, Vincentius Raki Mahindara, Ardyono Priyadi, and David Felipe Celeita Rodriguez; software, Vincentius Raki Mahindara, Eduard Muljadi, and Mauridhi Hery Purnomo; validation, David Felipe Celeita Rodriguez, Eduard Muljadi, and Mauridhi Hery Purnomo; formal analysis, Vincentius Raki Mahindara; investigation, Vincentius Raki Mahindara and Margo Pujiantara; resources, Ardyono Priyadi, Margo Pujiantara, Eduard Muljadi, and Mauridhi Hery Purnomo; data curation, Vincentius Raki Mahindara; writing - original draft preparation, Vincentius Raki Mahindara; writing - review and editing, David Felipe Celeita Rodriguez; visualization, Vincentius Raki Mahindara; supervision, Eduard Muljadi and Mauridhi Hery Purnomo; project administration, Margo Pujiantara and Ardyono Priyadi; funding acquisition, Mauridhi Hery Purnomo.

\section{Acknowledgments}

The lead author thanks the Auburn Clean Energy (ACE) Center at Auburn University for providing the materials and software used to develop some parts of the work presented in the paper. The lead and the corresponding author acknowledges the financial support funded by the Institut Teknologi Sepuluh 
Nopember on behalf of Indonesian Ministry of Education and Culture, under "Pendidikan Magister menuju Doktor untuk Sarjana Unggul (PMDSU)" grant No. 1271/PKS/ITS/2020.

\section{References}

[1] A. R. Haron, A. Mohamed, and H. Shareef, "Coordination of Overcurrent, Directional and Differential Relays for the Protection of Microgrid System”, Procedia Technol., Vol. 11, pp. 366-373, Jan. 2013, doi: 10.1016/j.protcy.2013.12.204.

[2] M. Singh, "Protection coordination in distribution systems with and without distributed energy resources- a review", Prot. Control Mod. Power Syst., Vol. 2, No. 1, p. 27, Jul. 2017, doi: 10.1186/s41601-017-0061-1.

[3] E. Dehghanpour, H. K. Karegar, R. Kheirollahi, and T. Soleymani, "Optimal Coordination of Directional Overcurrent Relays in Microgrids by Using Cuckoo-Linear Optimization Algorithm and Fault Current Limiter", IEEE Trans. Smart Grid, Vol. 9, No. 2, pp. 1365-1375, Mar. 2018, doi: 10.1109/TSG.2016.2587725.

[4] V. R. Mahindara, D. Celeita, M. Pujiantara, A. Priyadi, M. H. Purnomo, and E. Muljadi, "Modern Concerns and Challenges of OverCurrent Protection Coordination in Distribution Systems", In: Proc. of 2020 IEEE/IAS 56th Industrial and Commercial Power Systems Technical Conference (I CPS), pp. 1-7, 2020, doi: 10.1109/ICPS48389.2020.9176749.

[5] A. Hooshyar, and R. Iravani, "A New Directional Element for Microgrid Protection", IEEE Trans. Smart Grid, Vol. 9, No. 6, pp. 6862-6876, 2018, doi: 10.1109/TSG.2017.2727400.

[6] C. Yuan, M. A. Haj-ahmed, and M. S. Illindala, "Protection Strategies for Medium-Voltage Direct-Current Microgrid at a Remote Area Mine Site", IEEE Trans. Ind. Appl., Vol. 51, No. 4, pp. 2846-2853, 2015, doi: 10.1109/TIA.2015.2391441.

[7] D. Jones and J. J. Kumm, "Future Distribution Feeder Protection Using Directional Overcurrent Elements", IEEE Trans. Ind. Appl., Vol. 50, No. 2, pp. 1385-1390, 2014, doi: 10.1109/TIA.2013.2283237.

[8] H. M. Sharaf, H. H. Zeineldin, and E. ElSaadany, "Protection Coordination for Microgrids With Grid-Connected and Islanded Capabilities Using Communication Assisted Dual Setting Directional Overcurrent Relays",
IEEE Trans. Smart Grid, Vol. 9, No. 1, pp. 143151, 2018, doi: 10.1109/TSG.2016.2546961.

[9] B. Mahamedi, J. G. Zhu, M. Eskandari, J. E. Fletcher, and L. Li, "Protection of inverterbased microgrids from ground faults by an innovative directional element", IET Gener. Transm. Amp Distrib., Vol. 12, No. 22, pp. 5918-5927, 2018, doi: 10.1049/ietgtd.2018.5469.

[10] "IEEE Standard for Inverse-Time Characteristics Equations for Overcurrent Relays", IEEE Std C37.112-2018 Revis. IEEE Std C37.112-1996, pp. 1-25, 2019, doi: 10.1109/IEEESTD.2019.8635630.

[11] "IEC International Standard for Measuring relays and protection equipment - Part 151: Functional requirements for over/under current protection", IEC 60255-151, pp. 1-68, 2009.

[12] S. Jamali, and H. Borhani-Bahabadi, "Protection Method for Radial Distribution Systems With DG Using Local Voltage Measurements", IEEE Trans. Power Deliv., Vol. 34, No. 2, pp. 651-660, 2019, doi: 10.1109/TPWRD.2018.2889895.

[13] K. A. Saleh, H. H. Zeineldin, A. Al-Hinai, and E. F. El-Saadany, "Optimal Coordination of Directional Overcurrent Relays Using a New Time-Current-Voltage Characteristic", IEEE Trans. Power Deliv., Vol. 30, No. 2, pp. 537544, 2015, doi: 10.1109/TPWRD.2014.2341666.

[14] A. A. Balyith, H. M. Sharaf, M. Shaaban, E. F. El-Saadany, and H. H. Zeineldin, "NonCommunication Based Time-Current-Voltage Dual Setting Directional Overcurrent Protection for Radial Distribution Systems With DG", IEEE Access, Vol. 8, pp. 190572-190581, 2020, doi: 10.1109/ACCESS.2020.3029818.

[15] K. A. Saleh, and A. Mehrizi-Sani, "Harmonic Directional Overcurrent Relay For Islanded Microgrids With Inverter-Based DGs", IEEE Syst. J., pp. 1-12, 2020, doi: 10.1109/JSYST.2020.2980274.

[16] C. Marnay, C. Abbey, G. Joos, and WG C6.22, Microgrids Engineering, Economics, \& Experience, Vol. TB 635. CIGRE, 2015.

[17] R. Seguin, J. Woyak, D. Costyk, J. Hambrick, and B. Mather, "High-Penetration PV Integration Handbook for Distribution Engineers", National Renewable Energy Laboratory, Technical Report NREL/TP-5DOO63114, 2016.

[18] S. Beheshtaein, R. Cuzner, M. Savaghebi, and J. M. Guerrero, "Review on microgrids protection", IET Gener. Transm. Distrib., Vol. 
13, No. 6, pp. 743-759, 2019, doi: 10.1049/ietgtd.2018.5212.

[19] A. Ukil, B. Deck, and V. H. Shah, "CurrentOnly Directional Overcurrent Protection for Distribution Automation: Challenges and Solutions", IEEE Trans. Smart Grid, Vol. 3, No. 4, pp. 1687-1694, 2012, doi: 10.1109/TSG.2012.2208127.

[20] M. Basu, V. R. Mahindara, J. Kim, R. M. Nelms, and E. Muljadi, "Comparison of Active and Reactive Power Oscillation Damping with PV plants", IEEE Trans. Ind. Appl., Early Access, 2021, doi: 10.1109/TIA.2021.3059810.

[21] S.-E. Razavi, E. Rahimi, and J. P. S. Catalão, "Impact of distributed generation on protection and voltage regulation of distribution systems: A review", Renew. Sustain. Energy Rev., Vol. 105, pp. 157-167, 2019, doi: 10.1016/j.rser.2019.01.050.

[22] M. Higginson, F. Friend, and WG C30, Microgrid Protection Systems, Vol. PES-TR71. IEEE Power and Energy Society, 2019.

[23] R. M. Vincentius, A. W. Nugraha, P. S. Talitha, P. Margo, P. Ardyono, and H. P. Mauridhi, "Recognition of Electric Machines Boundary as The Constraint of Over Current Relay Coordination in Real Industrial Application with Serial Firefly Algorithm Optimization", In: Proc. of 2019 IEEE 12th International Symposium on Diagnostics for Electrical Machines, Power Electronics and Drives (SDEMPED), 2019, pp. 153-159, doi: 10.1109/DEMPED.2019.8864828.

[24] H. Gu, R. Yan, T. K. Saha, and E. Muljadi, "System Strength and Inertia Constrained Optimal Generator Dispatch under High Renewable Penetration", IEEE Trans. Sustain. Energy, pp. 1-1, 2019, doi: 10.1109/TSTE.2019.2957568.

[25] V. R. Mahindara, A. Priyadi, M. Pujiantara, M. H. Purnomo, A. Y. Saber, and E. Muljadi, "Protection Coordination Challenges for Microgrid Distribution Network with High Penetration Inverter-Based Resources”, In: Proc. of 2020 IEEE Energy Conversion Congress and Exposition (ECCE), 2020, pp. 1618-1622, doi: 10.1109/ECCE44975.2020.9235817.

[26] S. A. Saleh, C. Richard, X. F. St. Onge, J. Meng, and E. Castillo-Guerra, "Comparing the Performance of Protection Coordination and Digital Modular Protection for Grid-Connected Battery Storage Systems", IEEE Trans. Ind. Appl., Vol. 55, No. 3, pp. 2440-2454, 2019, doi: 10.1109/TIA.2018.2886891.
[27] "IEEE Standard Electrical Power System Device Function Numbers, Acronyms, and Contact Designations", IEEE Std C37.2-2008 Revis. IEEE Std C37.2-1996, pp. 1-48, Oct. 2008, doi: 10.1109/IEEESTD.2008.4639522.

[28] Schneider Electric, Sepam Series 80 Protective Relays Reference Manual. 2007.

[29] ABB, Relion Protection and Control REF630 series Technical Manual, 2019.

[30] Siemens, SIPROTEC 5 V7.80 and higher Overcurrent Protection 7SJ82/7SJ85, 2018.

[31] V. Gurevich, Electric Relays Princples and Applications, First. FL, USA: CRC Press Taylor \& Francis Group, 2006.

[32] J. M. Gers, and E. J. Holmes, Protection of Electricity Distribution Networks, Third. London, United Kingdom: The Institution of Engineering and Technology, 2011.

[33] M. Nagpal, and C. Henville, "Impact of PowerElectronic Sources on Transmission Line Ground Fault Protection", IEEE Trans. Power Deliv., Vol. 33, No. 1, pp. 62-70, 2018, doi: 10.1109/TPWRD.2017.2709279.

[34] A. Hooshyar, and R. Iravani, "Microgrid Protection", Proc. IEEE, Vol. 105, No. 7, pp. 1332-1353, 2017, doi: 10.1109/JPROC.2017.2669342.

[35] S. Rahmani, A. Rezaei-Zare, M. Rezaei-Zare, and A. Hooshyar, "Voltage and Frequency Recovery in an Islanded Inverter-Based Microgrid Considering Load Type and Power Factor", IEEE Trans. Smart Grid, Vol. 10, No. 6, pp. 6237-6247, 2019, doi: 10.1109/TSG.2019.2899912.

[36] C. S. Mardegan, and R. Rifaat, "Considerations in Applying IEEE Recommended Practice for Protection Coordination in Industrial and Commercial Power Systems-Part I", IEEE Trans. Ind. Appl., Vol. 52, No. 5, pp. 3705-3713, 2016, doi: 10.1109/TIA.2016.2563405.

[37] "IEEE Recommended Practice for Protection and Coordination of Industrial and Commercial Power Systems (IEEE Buff Book)", IEEE Std 242-2001 Revis. IEEE Std 242-1986 IEEE Buff Book, pp. 1-710, 2001, doi: 10.1109/IEEESTD.2001.93369.

[38] V. R. Mahindara, D. F. C. Rodriguez, M. Pujiantara, A. Priyadi, M. H. Purnomo, and E. Muljadi, "Practical Challenges of Inverse and Definite-Time Overcurrent Protection Coordination in Modern Industrial and Commercial Power Distribution System", IEEE Trans. Ind. Appl., Vol. 57, No. 1, pp. 187-197, 2021, doi: 10.1109/TIA.2020.3030564. 